\title{
Spreading and scaling up innovation and improvement
}

\author{
(c) $(\mathbb{\theta} \Theta$ OPEN ACCESS \\ Disseminating innovation across the healthcare system is challenging but potentially achievable \\ through different logics: mechanistic, ecological, and social, say Trisha Greenhalgh and Chrysanthi \\ Papoutsi
}

\section{Trisha Greenhalgh professor, Chrysanthi Papoutsi postdoctoral researcher}

Primary Care Health Sciences, University of Oxford, Oxford OX2 6GG, UK

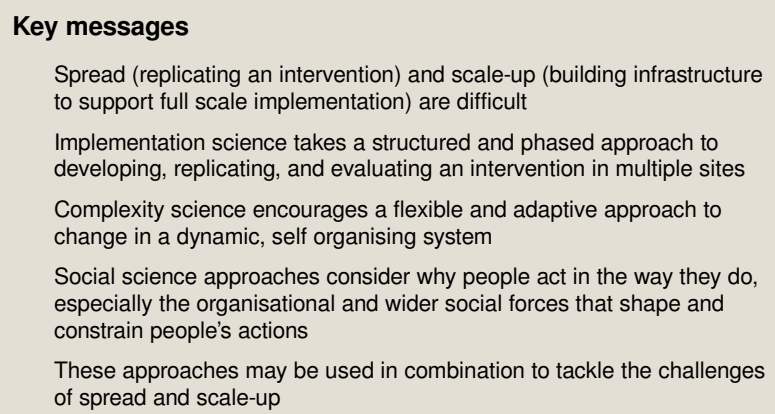

The general practitioner in the surgery, the nurse manager on the ward, and the policy maker in the boardroom would be forgiven for losing track of all the new technologies, care pathways, and service models that could potentially improve the quality, safety, or efficiency of care. Yet we know that innovations rarely achieve widespread uptake even when there is robust evidence of their benefits (and especially when such evidence is absent or contested). ${ }^{1}$ The NHS Long Term Plan points out that every approach prioritised in the plan is already happening somewhere in the NHS but has not yet been widely adopted. $^{2}$

There are common sense reasons why spreading an innovation across an entire health system is hard. Achieving any change takes work, and it usually also involves - in various combinations-spending money, diverting staff from their daily work, shifting deeply held cultural or professional norms, and taking risks. Simplistic metaphors ("blueprint," "pipeline," "multiplier") aside, there is no simple or universally replicable way of implementing change at scale in a complex system. A technology or pathway that works smoothly in setting A will operate awkwardly (or not at all) in setting B.
Given these realities, what insights does the rapidly growing research literature on spread and scale-up offer the busy clinician, manager, commissioner, or policy maker? How-if at all-does this literature speak to the patient?

"Spread" generally means replicating an initiative somewhere else and "scale-up" means tackling the infrastructural problems (across an organisation, locality, or health system) that arise during full scale implementation, ${ }^{3}$ though in practice the one blurs into the other.

In this rapid review (the methods of which are described in box 1) we found that scholars of spread and scale-up had used many different theoretical lenses. We have chosen to discuss three-implementation science, complexity science, and social science, each of which is based on a different logic of change (mechanical, ecological, and social, respectively; table 1). Many successful spread and scale-up programmes draw predominantly on one of these lenses but include elements of the other two.

\section{Box 1: Search methods and summary of dataset}

Through a keyword and snowball search, we identified recent systematic reviews, narrative reviews, realist reviews, and theoretical syntheses on spread or scale-up (see supplementary file). Each had a different focus, such as improvement science in high income ${ }^{46}$ and low and middle income countries, ${ }^{378}$ innovation in primary care ${ }^{9}$ or public health, ${ }^{10}$ complex interventions, leadership for innovation, ${ }^{12}$ the social practice of innovation, ${ }^{13}$ and technology adoption. ${ }^{1415}$

All these reviews emphasised the need to attend to the complex relationship between intervention, people, organisation, and the wider context, but they used different conceptual frameworks and theoretical lenses.

Prompted by a reviewer of an earlier draft of this paper, we searched the literature for reviews that had explicitly considered how patients might be involved in spread and scale-up efforts. We found no such reviews so removed the "review" filter from our search and selected one relevant, high quality, primary study. 


\section{Implementation science: spread and scale-up as structured improvement}

Implementation science, defined as "the scientific study of methods to promote the systematic uptake of research findings and other evidence based practices into routine practice" (page 2), ${ }^{16}$ developed from the evidence based medicine movement in Europe and North America. It is perhaps best known for the sequential, structured (and somewhat top-down) method of spreading focused improvement techniques. ${ }^{1016}$

The first phase of this approach (after initial set-up and orientation) is the development of a clearly defined intervention, the components of which are optimised to reflect the evidence base (especially relating to how to change individual behaviour) (fig 1). There is then a small scale trial of this intervention in one or a few selected settings, followed by a systematic effort to replicate it in other settings, partly by identifying and dealing with barriers (which get in the way of the implementation effort) and facilitators (which potentially support it).

Patient input can be harnessed very productively in this effort, though careful attention needs to be paid to power dynamics, the kinds of data that are collected, and how and by whom those data are analysed. ${ }^{15}$

Although the sequence depicted in figure 1 is often promoted as the key to quality improvement, one systematic review showed that nearly half of all successful scale-up initiatives had not followed it. ${ }^{10}$

Implementation science approaches tend to draw heavily on quality improvement methodology. Barker and colleagues describe this methodology as an "engine" that uses rapid cycle change to drive spread of an innovation, with some potential to adapt to different contexts. ${ }^{3}$

In recent years, implementation science has matured as a field in a way that has paralleled developments in the Medical Research Council's guidance for developing and testing complex interventions. ${ }^{17}$ Both have shifted from a highly structured and narrowly experimental approach based on mechanical logic (which emphasised standardisation and replicability) to a more adaptive approach that recognises the need to think flexibly, understand and respond to local context, use qualitative methods to explore processes and mechanisms, and adapt the intervention to achieve best fit with different settings. ${ }^{18}$ This shift resonates with the complexity science approach described in the next section.

An example of spread using an implementation science logic is shown in box 2 .
Box 2: An implementation science approach to spread and scale-up

McKay and colleagues followed the full sequence of efficacy, effectiveness, and implementation trials to develop, test, and scale up an intervention of physical activity and healthy eating in elementary schools in British Colombia, Canada. ${ }^{19}$ In the first phase, the multifaceted intervention (consisting of resources, training for teachers, school facilitators, and a regional support team) was developed through participatory research with schools, communities, and other stakeholders, taking account of contextual realities, behaviour change, and social-ecological theories.

Efficacy was evaluated in a cluster randomised controlled trial in 10 schools, which measured four outcomes: school based opportunities for physical activity; actual physical activity levels; students' chronic disease risk factors (such as obesity) and academic performance; and students' self reported consumption of vegetables and fruit. Process evaluation captured contextual and operational issues that led to refinement of the intervention, which was then evaluated for effectiveness under real world conditions in a larger cluster randomised

controlled trial.

In the implementation and scale-up phase, a further 348 schools were supported to adopt and embed the intervention (with attention to fidelity of key components) and evaluate its effect locally. At the time of publication, 225 trained regional trainers had delivered over 4000 workshops to train over 80 000 teachers, reaching approximately 500000 students. The programme, which took six years to develop and pilot, was sustained over 10 years. This is a rare example of a predominantly top-down (structured and programmatic) spread and scale-up strategy that achieved widespread coverage and measurable improvements in some but not all outcome measures. Its success, however, is also likely to be attributable to the use of participatory research and social-ecological theories and to a positive policy context, strong professional buy-in, generous resourcing, and long timescale.

\section{Complexity science: spread and scale-up as adaptive change}

A complex system is a set of things, people, and processes that evolve dynamically and can be defined in terms of their relationships and interactions. ${ }^{418}$ Such systems are characterised by uncertainty, unpredictability, and emergence. They adapt through self organisation (such as continuous adaptations initiated by frontline staff to allow them to complete tasks given local contingencies and availability of resources), attention to interdependencies (how the parts of the system fit together), and sensemaking (the process by which people, individually and collectively, assign meaning to experience and link it to action). ${ }^{4}$

To study the ecological (that is, emergent, interdependent, adaptive) properties of complex systems, researchers and evaluators use multiple methods, particularly ethnographic observation, in real world settings. Such studies are usually written up as richly described case studies incorporating both quantitative and qualitative data and including a narrative of how and why things changed over time.

Complexity can be hard to square with spread strategies that seek to replicate a "blueprint" innovation in a standardised way across widely different settings. The plan-do-study-act engine depicted in figure 1 might work for small scale improvement initiatives, but spreading and scaling up major innovations across a health system requires attention to the underlying logic of complex systems, which is ecological rather than mechanical. $^{4578}$

Lanham and colleagues, for example, recommend the following principles when planning major change programmes in conditions of complexity ${ }^{4}$ :

Acknowledge unpredictability - designers of interventions should contemplate multiple plausible futures;

implementation teams should tailor designs to local context and view surprises as opportunities

Recognise self organisation-designers should expect their designs to be modified, perhaps extensively, as they are taken 
up in different settings; implementation teams should actively capture data and feed it into the adaptation process

Facilitate interdependencies - designers should develop methods to assess the nature and strength of interdependencies; implementation teams should attend to these relationships, reinforcing existing ones where appropriate and facilitating new ones

Encourage sensemaking - designers should build focused experimentation into their designs; implementation teams should encourage participants to ask questions, admit ignorance, explore paradoxes, exchange different viewpoints, and reflect collectively.

To this list, we would add:

Develop adaptive capability in staff_-individuals should be trained not merely to complete tasks as directed but to tinker with technologies and processes and make judgments when faced with incomplete or ambiguous data

Attend to human relationships - embedding innovation requires people to work together to solve emergent problems using give-and-take and "muddling through"

Harness conflict productively - there is rarely a single, right way of tackling a complex problem, so view conflicting perspectives as the raw ingredients for multifaceted solutions.

These principles underpin the concept of the learning health system, defined as one "in which science, informatics, incentives, and culture are aligned for continuous improvement and innovation, with best practices seamlessly embedded in the delivery process and new knowledge captured as an integral by-product of the delivery experience" (page 17).$^{20} \mathrm{~A}$ learning health system is characterised by participatory culture, distributed leadership, engaged patients, shared and evidence based decision making, transparent assessment of outcomes, and use of information and technology for continuous learning. Innovation, improvement, spread, and scale-up will all occur more readily in such a system. ${ }^{20}$

There are numerous specific models of spread and scale-up that embrace (implicitly or explicitly) ecological logic and the learning health system; some are listed in table 2.

An example of a complexity science approach to scale-up and spread is shown in box 3. It shows that although the success of an initiative based on implementation science can be measured by fidelity of its replication across a range of contexts, success of a change effort in different parts of a complex system is better measured by a nuanced account of what changed and why. ${ }^{22}$
Box 3: A complexity science approach to spread and scale-up

Eaton and colleagues used a combination of systematic review and national stakeholder interviews to build up an international case study of challenges to the spread of evidence based mental health programmes in low and middle income countries. ${ }^{8}$ Although every country had its own unique problems, some inter-related challenges recurred: limited financial resources and government commitment; overcentralisation of services in large psychiatric hospitals along with a weak, underfunded primary care sector; scarcity of trained mental health personnel; and low public health expertise among mental health leaders. In the context of such widespread problems, the term scale-up was extended to refer to several linked goals: increase coverage (the number of people receiving mental health services); increase the range and appropriateness of services offered; increase the extent to which these services were evidence based (using service models that had been tested in comparable settings); and strengthen the mental healthcare system through policy formulation, implementation planning, and financing. Also key to the spread and scale-up effort were mobilising political will and reducing the stigma of mental health conditions among both lay people and health professionals. Seen through a complexity lens, all these goals are interdependent and mutually reinforcing. Numerous approaches were taken in different countries at national level (including attempts to influence the prioritisation, planning, and resource allocation for mental health services; challenging the tertiary care focus; developing and disseminating evidence based guidelines; developing human resource policies and programmes) and local level (support for service restructuring; training programmes for primary care staff in common mental disorders; engagement and education of patients, families, and communities; and strengthening systems for evaluation and monitoring). Many settings were found to have weak data systems. By improving the quality of routinely collected data, developing reliable metrics of success that fed into system planning in a timely way, and developing links with academic researchers, the potential for system learning was greatly improved, though the spread and scale-up effort was more successful in some settings than others.

In contrast with the example in box 1 , a highly programmatic top-down approach emphasising fidelity of an intervention would not have worked in this case. An adaptive approach, combining national policy efforts with bottom-up strengthening of local services, was needed to take account of the precarious political and economic context in many low and middle income countries and the multiple interdependencies in the system.

\section{Social science: spread and scale-up as social action}

Social science approaches seek to identify and explain social mechanisms, such as what people believe and feel; why people act as they do; how they interpret material artefacts and other people's actions; and how they draw on programme resources to achieve their goals (or why they refuse or are unable to do so).

As the previous section emphasised, staff in organisations implement change creatively and adaptively rather than mechanically. They experiment with innovations, develop feelings (positive or negative) about them, worry about them, adapt them to particular tasks, "work around" them, and try to redesign them. ${ }^{1}$ Efforts to standardise the replication of an intervention across multiple settings therefore rarely go to plan.

Social science approaches to scale and spread generate theories about why and how programmes of change diverge from initial plans over time: explanations that answer the question, "What did people do in this particular case and why did that have the effect it did?" A programme theory is expressed at a very low level of generality (that is, it may apply only to the case being analysed and closely comparable settings)—for example, "The nurses did not engage because of a staffing crisis." Social scientists also develop more general ("substantive") theories to explain why spread and scale-up did or did not happen-for example, theories of behaviour change (individual level), absorptive capacity (organisational level), or interorganisational influence (supra-organisational level). Usually, a social science explanation of a spread or scale-up effort requires both substantive theory (or theories) and a more specific programme theory. ${ }^{11} 1323$

Shaw and colleagues synthesised various substantive theories (summarised in the supplementary file) that have been used to 
analyse the spread and scale-up effort as social practice. ${ }^{13}$ These theories-which include normalisation process theory, actor-network theory, and structuration theory-help researchers and change agents to tap into (with a view to influencing) the organisational and societal influences that shape and constrain individuals' actions. What do patients expect? What do different professional groups define as the gold standard of excellence? What do different professionals on the team expect of each other? What is thought to be legally sanctioned (whether or not correct)?

Many social scientists view the organisation as a "meso" level world that mediates between the individual (micro) and societal (macro). Individuals' actions in organisations are seen as shaped not only by practical and material realities but also by what are known as scripts or routines- that is, expected or required patterns of behaviour defined by formal roles, regulations, and standard operating procedures as well as by informal customs, practices, and traditions. ${ }^{24}$ Organisational routines, in turn, are strongly influenced by external social forces including professional norms, public expectations, laws and policies, and commercial and other vested interests.

Organisational change can thus be viewed as inherently transgressive, because doing things differently violates the norms, expectations, and rules that are inscribed in organisational routines. Yet because routines are carried out by creative, thinking individuals rather than automatons, they contain the scope for adaptation and change..$^{24}$ Leaders-clinical, managerial, and perhaps most importantly hybrid leaders who bridge both these roles-have a crucial part in creating the preconditions in which staff will feel confident to innovate and improve (for example, by setting a climate of risk taking and collaborative learning rather than one of playing safe and covering one's back). ${ }^{312}$ An example of how social science has informed a study of spread and scale-up is shown in box 4 .

\section{Box 4: A social science approach to spread and scale-up}

A good example of how researchers used social theory to explain both spread and non-spread of innovations are Dixon-Woods and colleagues' studies of national efforts to reduce catheter associated infections in intensive care units in the United States ${ }^{23}$ (highly successful) and United Kingdom (less successful). ${ }^{25}$

The US investigators had initially concluded (using an implementation science lens) that a technical checklist, introduced in over 100 intensive care units, had dramatically reduced rates of central venous catheter infection by making the care process more systematic, rational, consistent, and evidence based. Dixon-Woods and her colleagues undertook post hoc interviews, reanalysed the data, and came up with a new theory of spread that was predominantly social rather than technical.

They showed, for example, that the US programme came to be seen as something a "good" intensive care unit should be signing up to, perhaps because it was led by respected opinion leaders from a university. Relations between participating units strengthened as a result of participation, resulting in extensive interorganisational networking and lateral support. As the initiative evolved, it took on the characteristics of a grassroots social movement in which responsible clinicians and managers identified strongly with the programme and wanted to be involved.

A later ethnographic study by the same team ${ }^{25}$ used a different programme theory to explain why the same intervention largely failed to spread in UK intensive care units, despite a nearly identical phased model of implementation. In the UK, the intervention was seen as top-down and driven by government rather than professionally led and collaborative; the initiative was introduced in parallel with other major infection control policies so had a less distinct identity; there was limited lateral support between participating units; and in low performing units there appeared to be a history of under-resourced improvement initiatives that had resulted in change fatigue.

This case took a social science approach in the sense that a detailed programme theory was developed to explain both high and low success in different contexts, though the original design had been a conventional (largely behavioural) implementation science intervention.

\section{Conclusion}

We have presented three different logics through which spread and scale-up can be approached: mechanistic (implementation science), ecological (complexity science), and social (social science). We have separated them for analytic purposes, but there are substantial synergies and overlaps between them. These approaches can inform the design and implementation of spread and scale-up programmes from small quality improvement interventions to system-wide transformational change and can offer insights to frontline teams about how and why particular change efforts are effective (or not). Empirical studies of spread and scale-up can, and perhaps should, combine more than one perspective. As a rule of thumb, the larger, more ambitious, and more politically contested the spread challenge, the more ecological and social practice perspectives will need to supplement (or replace) "mechanical" efforts to replicate an intervention.

For further reading on the interface between implementation science, complexity science, and social practice, we recommend Braithwaite and colleagues' recent theoretical synthesis. ${ }^{26}$

Competing interests: We have read and understood BMJ policy on declaration of interests and declare the following interests: none.

Patient and public involvement: Patients and the public were not involved directly in this review article. The methodology included a specific search for studies in which patients and the public were involved in spread and scale-up projects. Funding: TG is funded by the National Institute for Health Research Biomedical Research Centre, Oxford; grant BRC-1215-20008 to the Oxford University Hospitals NHS Foundation Trust and the University of Oxford. Funders had no say in the planning, execution, or writing up of the paper.

This article is part of a series commissioned by The BMJ based on ideas generated by a joint editorial group with members from the Health Foundation and The BMJ, including a patient/carer. The BMJ retained full editorial control over external peer review, editing, and publication. Open access fees and The BMJ's quality improvement editor post are funded by the Health Foundation

1 Greenhalgh T, Robert G, Macfarlane F, Bate P, Kyriakidou O. Diffusion of innovations in service organizations: systematic review and recommendations. Milbank $Q$ 2004;82:581-629. 10.1111/j.0887-378X.2004.00325.x 15595944

2 NHS England. NHS long term plan. NHS England, 2019.

3 Barker PM, Reid A, Schall MW. A framework for scaling up health interventions: lessons from large-scale improvement initiatives in Africa. Implement Sci 2016;11:12. 10.1186/s13012-016-0374-x 26821910

4 Lanham HJ, Leykum LK, Taylor BS, McCannon CJ, Lindberg C, Lester RT. How complexity science can inform scale-up and spread in health care: understanding the role of self-organization in variation across local contexts. Soc Sci Med 2013;93:194-202. 10.1016/j.socscimed.2012.05.040 22819737

5 Øvretveit J, Garofalo L, Mittman B. Scaling up improvements more quickly and effectively. Int J Qual Health Care 2017;29:1014-9. 10.1093/intghc/mzx147 29177491

6 Leeman J, Birken SA, Powell BJ, Rohweder C, Shea CM. Beyond "implementation strategies": classifying the full range of strategies used in implementation science and practice. Implement Sci 2017;12:125. 10.1186/s13012-017-0657-x 29100551

7 Øvretveit J. Widespread focused improvement: lessons from international health for spreading specific improvements to health services in high-income countries. Int J Qual Health Care 2011;23:239-46. 10.1093/intghc/mzr018 21536592

8 Eaton J, McCay L, Semrau M, etal . Scale up of services for mental health in low-income and middle-income countries. Lancet 2011;378:1592-603. 10.1016/S0140-6736(11)60891-X 22008429

9 Ben Charif A, Zomahoun HTV, LeBlanc A, etal . Effective strategies for scaling up evidence-based practices in primary care: a systematic review. Implement Sci2017;12:139. 10.1186/s13012-017-0672-y 29166911

10 Indig D, Lee K, Grunseit A, Milat A, Bauman A. Pathways for scaling up public health interventions. BMC Public Health 2017;18:68. 10.1186/s12889-017-4572-5 28764785

11 Willis $\mathrm{CD}$, Riley BL, Stockton L, etal . Scaling up complex interventions: insights from a realist synthesis. Health Res Policy Syst 2016;14:88.

10.1186/s12961-016-0158-4 27993138

12 Currie G, Spyridonides D. Sharing leadership for diffusion of innovation in professionalized settings. Hum Relat 2019; [forthcoming].

13 Shaw J, Shaw S, Wherton J, Hughes G, Greenhalgh T. Studying scale-up and spread as social practice: theoretical introduction and empirical case study. J Med Internet Res 2017;19:e244. 10.2196/jmir.7482 28687532

14 Greenhalgh T, Wherton J, Papoutsi C, etal . Beyond adoption: a new framework for theorizing and evaluating nonadoption, abandonment, and challenges to the scale-up, spread, and sustainability of health and care technologies. $J$ Med Internet Res 2017;19:e367. 10.2196/jmir.8775 29092808 
15 Renedo A, Marston CA, Spyridonidis D, etal . Patient and public involvement in healthcare quality improvement: how organizations can help patients and professionals to collaborate. Public Manage Rev 2015;17:17-3410.1080/14719037.2014.881535.

16 Nilsen P. Making sense of implementation theories, models and frameworks. Implement Sci 2015;10:53. 10.1186/s13012-015-0242-0 25895742

17 Craig P, Dieppe P, Macintyre S, Michie S, Nazareth I, Petticrew MMedical Research Council Guidance. Developing and evaluating complex interventions: the new Medical Research Council guidance. BMJ 2008:337:a1655. 10.1136/bmj.a1655 18824488

18 Greenhalgh T, Papoutsi C. Studying complexity in health services research: desperately seeking an overdue paradigm shift. BMC Med 2018;16:95. 10.1186/s12916-018-1089-4 29921272

19 McKay HA, Macdonald HM, Nettlefold L, Masse LC, Day M, Naylor PJ. Action Schools! $\mathrm{BC}$ implementation: from efficacy to effectiveness to scale-up. Br J Sports Med 2015:49:210-8. 10.1136/bjsports-2013-093361 25312876

20 Institute of Medicine Round Table on Value and Science-Driven Healthcare. The learning health system and its innovation collaboratives, page 13. http://www.nationalacademies. org/hmd/Activities/Quality/ /media/Files/Activity\%20Files/Quality/VSRT/Core\% 20Documents/ForEDistrib.pdf. National Academy of Medicine, 2011.

21 Bate $\mathrm{P}$, Robert $\mathrm{G}$. Experience-based design: from redesigning the system around the patient to co-designing services with the patient. Qual Saf Health Care 2006;15:307-10. 10.1136/qshc.2005.016527 17074863
22 Greenhalgh T, Macfarlane F, Barton-Sweeney C, Woodard F. "If we build it, will it stay?" A case study of the sustainability of whole-system change in London. Milbank $Q$ 2012;90:516-47. 10.1111/j.1468-0009.2012.00673.x 22985280

23 Dixon-Woods M, Bosk CL, Aveling EL, Goeschel CA, Pronovost PJ. Explaining Michigan: developing an ex post theory of a quality improvement program. Milbank $Q$ 2011;89:167-205. 10.1111/j.1468-0009.2011.00625.x 21676020

24 Greenhalgh T. Role of routines in collaborative work in healthcare organisations. BMJ 2008;337:a2448. . 10.1136/bmj.a2448 19015186

25 Dixon-Woods M, Leslie M, Tarrant C, Bion J. Explaining Matching Michigan: an ethnographic study of a patient safety program. Implement Sci 2013;8:70 10.1186/1748-5908-8-70 23786847

26 Braithwaite J, Churruca K, Long JC, Ellis LA, Herkes J. When complexity science meets implementation science: a theoretical and empirical analysis of systems change. BMC Med 2018;16:63. 10.1186/s12916-018-1057-z 29706132

Published by the BMJ Publishing Group Limited. For permission to use (where not already granted under a licence) please go to http://group.bmj.com/group/rights-licensing/ permissionsThis is an Open Access article distributed in accordance with the Creative Commons Attribution Non Commercial (CC BY-NC 4.0) license, which permits others to distribute, remix, adapt, build upon this work non-commercially, and license their derivative works on different terms, provided the original work is properly cited and the use is non-commercial. See: http://creativecommons.org/licenses/by-nc/4.0/. 


\section{Tables}

\begin{tabular}{|c|c|c|c|}
\hline & Implementation science & Complexity science & Social science \\
\hline Main focus & Evidence based interventions in practice & The evolving and emergent properties of systems & $\begin{array}{c}\text { Social study of individuals, groups, and } \\
\text { organisations }\end{array}$ \\
\hline Contribution & $\begin{array}{l}\text { Provides a concrete, planned approach } \\
\text { to the delivery and study of spread and } \\
\text { scale-up }\end{array}$ & $\begin{array}{l}\text { Ecological view that emphasises the system's } \\
\text { inherent unpredictability and need for adaptive } \\
\text { change at multiple, interacting levels }\end{array}$ & $\begin{array}{l}\text { Foregrounds patterns of social behaviour and } \\
\text { interaction, professional beliefs and values, } \\
\text { and organisational routines and structures }\end{array}$ \\
\hline $\begin{array}{l}\text { Key mechanisms of } \\
\text { spread and scale-up }\end{array}$ & $\begin{array}{l}\text { Uncertainty reduction, emphasis on } \\
\text { fidelity and contextual influences }\end{array}$ & $\begin{array}{l}\text { Emergent properties of an interacting system-self } \\
\text { organisation, management of interdependencies, } \\
\text { and sense making }\end{array}$ & $\begin{array}{l}\text { Social, professional, and organisational } \\
\text { influences that shape (and are shaped by) } \\
\text { individual and collective action }\end{array}$ \\
\hline $\begin{array}{l}\text { Preferred methods for } \\
\text { achieving spread and } \\
\text { scale-up }\end{array}$ & $\begin{array}{c}\text { Use structured, programmatic } \\
\text { approaches to develop and replicate a } \\
\text { complex intervention across multiple } \\
\text { settings }\end{array}$ & $\begin{array}{l}\text { Gain a rich understanding of the case in its } \\
\text { historical, sociopolitical, and organisational context. } \\
\text { Use multiple methods flexibly and adaptively. } \\
\text { Expect surprises and handle them creatively. } \\
\text { Develop individuals and organisations to be } \\
\text { creative and resilient }\end{array}$ & $\begin{array}{l}\text { Develop and apply theories of how } \\
\text { individuals' behaviour and actions are } \\
\text { influenced by interpersonal, material, } \\
\text { organisational, professional, and other factors }\end{array}$ \\
\hline $\begin{array}{l}\text { Preferred methods for } \\
\text { researching spread and } \\
\text { scale-up }\end{array}$ & $\begin{array}{c}\text { Metrics for measuring improvement } \\
\text { (quantitatively) and systematic approach } \\
\text { to exploring processes and mechanisms } \\
\text { (qualitatively) }\end{array}$ & $\begin{array}{c}\text { Case study approach using multiple qualitative and } \\
\text { quantitative methods. Narrative can be used as a } \\
\text { synthesising tool to capture complex chains of } \\
\text { causation }\end{array}$ & $\begin{array}{l}\text { Ethnography, interview based methods, and } \\
\text { case narratives to provide insights into social } \\
\text { interactions and contexts }\end{array}$ \\
\hline $\begin{array}{l}\text { How success is } \\
\text { measured }\end{array}$ & $\begin{array}{l}\text { Replication of a particular service model } \\
\text { or approach in multiple contexts } \\
\text { ("fidelity") }\end{array}$ & $\begin{array}{l}\text { Nuanced narrative about what changed and why, } \\
\text { including (where relevant) how the intervention was } \\
\text { adapted or why it was abandoned }\end{array}$ & $\begin{array}{l}\text { Theoretically informed and empirically } \\
\text { justified explanations about human and } \\
\text { organisational behaviour }\end{array}$ \\
\hline
\end{tabular}




\section{Table 2| Specific models for applying complexity science to spread and scale-up}

\begin{tabular}{|c|c|c|}
\hline Name of model (author, year) & Key components & Comment \\
\hline $\begin{array}{l}\text { Participatory adaptation (Øvretveit, } \\
2010)^{7}\end{array}$ & $\begin{array}{l}\text { In the context of international health, use of decentralised planning, } \\
\text { pragmatic modification, and improvement facilitators to adapt the } \\
\text { operational details of an intervention to local circumstances }\end{array}$ & $\begin{array}{l}\text { Proposed as a flexible way of achieving standardisation, } \\
\text { replication, and accountability while also respecting } \\
\text { emergence and adaptation at the local level }\end{array}$ \\
\hline $\begin{array}{l}\text { Facilitated evolution (Øvretveit, } \\
2010)^{7}\end{array}$ & $\begin{array}{l}\text { Local sites are supported to develop the capacity to find, adapt, and } \\
\text { develop practices and models of care that tackle the challenges they } \\
\text { face, with no external expectation placed on how problems are framed } \\
\text { or which solutions are to be adopted. Draws on the concept of resilience } \\
\text { (defined as a system's capability to withstand and recover from internal } \\
\text { tensions and external shocks) }\end{array}$ & $\begin{array}{l}\text { More radical approach than participatory adaptation. In } \\
\text { one example, the goal of preventing HIV/AIDS in a low } \\
\text { income African community was achieved through a } \\
\text { community development initiative, which provided women } \\
\text { with independent income }\end{array}$ \\
\hline $\begin{array}{l}\text { 3S scale-ı } \\
\text { (Øvretveit }\end{array}$ & $\begin{array}{l}\text { A combination of strat } \\
\text { data captur }\end{array}$ & \multirow{2}{*}{$\begin{array}{l}\text { These should not be viewed as mechanical tools to be } \\
\text { applied deterministically to "solve" complexity (though } \\
\text { formulaic versions of the breakthrough collaborative } \\
\text { model exist). Rather, they are broad approaches that } \\
\text { might be used creatively and reflexively to manage } \\
\text { complexity }\end{array}$} \\
\hline $\begin{array}{l}\text { Breakthrough collaboratives } \\
(\varnothing \text { vretveit, 2011) }\end{array}$ & $\begin{array}{c}\text { Provision of resources, infrastructure, and impetus for } \\
\text { inter-organisational exchange of resources, stories, and ideas oriented } \\
\text { to achieving an improvement goal-typically through periodic } \\
\text { collaborative workshops }\end{array}$ & \\
\hline $\begin{array}{l}\text { Experience based co-design (Bate } \\
\text { and Robert, 2006) }\end{array}$ & $\begin{array}{l}\text { In collaborative workshops and in preparatory and follow-up work, } \\
\text { patients work together with staff to identify emotional "touch points" in } \\
\text { the patient journey and redesign the service in a way that centres on } \\
\text { improving the patient experience }\end{array}$ & $\begin{array}{l}\text { Not explicitly focused on complexity but follows many of } \\
\text { the principles of effective change in complex } \\
\text { systems-notably self organisation, collective } \\
\text { sensemaking, and harnessing conflict productively }\end{array}$ \\
\hline
\end{tabular}




\section{Figure}

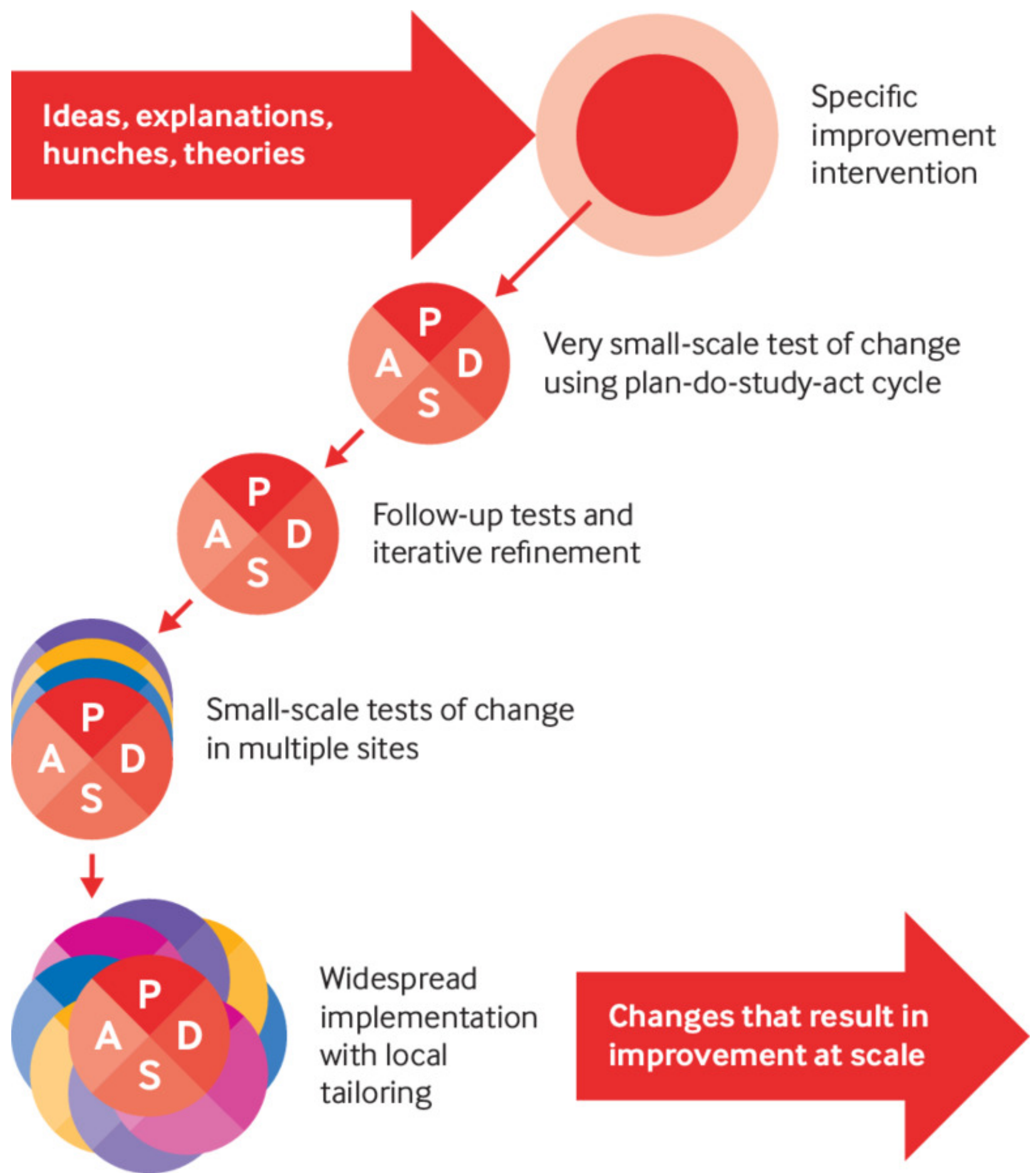

Fig 1 Rapid cycle test of change model of spread used in implementation science. Drawing on insights and a previous diagram in a review by Barker ${ }^{3}$ 